\title{
Distribution and effect of steroidal saponin derivative WRC3 in B16 melanoma cells
}

\author{
ZELIANG WEI ${ }^{1}$, YUYAN LIANG ${ }^{1}$, LIMEI MA ${ }^{1}, \mathrm{KE} \mathrm{LI}^{1}$, HAI NIU $^{2}$ and WEN HUANG ${ }^{1}$ \\ ${ }^{1}$ Laboratory of Ethnopharmacology, Regenerative Medicine Research Center, \\ Institute for Nanobiomedical Technology and Membrane Biology, West China Hospital, \\ West China Medical School, Sichuan University, Chengdu, Sichuan 610041; \\ ${ }^{2}$ College of Mathematics, Sichuan University, Chengdu, Sichuan 610064, P.R. China
}

Received October 21, 2014; Accepted July 7, 2015

DOI: $10.3892 / \mathrm{mmr} .2015 .4225$

\begin{abstract}
Steroidal saponins have recently attracted attention due to their structural diversity and significant biological activities, including anti-hyperlipidemic, antibacterial, anti-inflammatory, immunomodulatory and anti-HIV activities. In the present study, it was demonstrated that WRC3, a novel saponin derivative, can inhibit B16 cancer cells by inducing apoptotic cell death with an $\mathrm{IC}_{50}$ value of $12.09 \mu \mathrm{M}$. The inhibitory effect of WRC3 on B16 cells appears to occur in a time- and concentration-dependent manner. The fluorescence distribution observed by confocal microscopy revealed that WRC3 entered cells and acted in the cytoplasm without causing genetic toxicity. Following administration of WRC3 (2.5, 5.0 and $7.5 \mathrm{~g} / \mathrm{kg}$ body weight) once a day for 7 days, no obvious abnormalities were observed in the organs of the mice as demonstrated by hematoxylin and eosin staining. Compared with the normal control group, aspartate transaminase (AST), alanine transaminase (ALT), creatine and urea levels in the serum of mice treated with WRC3 $(2.5-7.5 \mu \mathrm{M})$ remained unchanged. In conclusion, it was demonstrated that WRC3 can induce cancer cell death without causing genetic toxicity, hepatotoxicity or nephrotoxicity.
\end{abstract}

\section{Introduction}

Diosgenin, isolated from Dioscorea zingiberensis C.H. Wright, is used as a raw material to synthesize WRC3, and is widely distributed throughout China $(1,2)$. Diosgenin has

Correspondence to: Professor Wen Huang, Laboratory of Ethnopharmacology, Regenerative Medicine Research Center, Institute for Nanobiomedical Technology and Membrane Biology, West China Hospital, West China Medical School, Sichuan University, 1 Keyuan 4 Road, Gaopeng Avenue, Hi-Tech Zone, Chengdu, Sichuan 610041, P.R. China

E-mail: huangwen@scu.edu.cn

Key words: diosgenyl analog, proliferation, apoptosis, distribution, acute toxicity been extensively used in traditional Chinese medicine for the treatment of various diseases $(1,2)$. Steroidal saponins have recently attracted attention due to their structural diversity and significant biological activities (3), including anticancer, anti-hyperlipidemia, anti-inflammatory (4), hemolytic, antibacterial, anti-thrombotic (5), immunomodulatory (6) and anti-HIV activities. Tong et al (7) and Rivera et al (8) reported that seven steroidal saponins isolated from Dioscorea zingiberensis $\mathrm{C}$.H. Wright were cytotoxic and resulted in the apoptosis of cancer cells. Kvasnica et al (9) reported that the twelve steroidal derivatives, platinum (II) complexes with steroidal esters of 1-histidine and 1-methionine, exhibited significant effects against the CEM T-lymphoblastic leukemia cell line with $\mathrm{IC}_{50}$ values in the range of $14-25 \mu \mathrm{M}$ (10). However, the site of action of the effective compounds remains to be understood and the precise mechanisms are not clear.

In recent years, our group has focused on identifying novel saponins from Dioscorea zingiberensis C.H. Wright and synthesizing new compounds of diosgenin with glucosyl, as well as determining the acute toxicity (11) and sub-chronic toxicity, the structure-activity relationships, and the pharmaceutical activities of the natural and modified steroidal saponins. Tong et al (7) reported that the sugar moiety of steroidal saponins may be crucial in the cytotoxic activity against cancer cell lines. A saponin derivative, WRC3 synthesized by our laboratory, has previously been shown to exhibit an anti-thrombotic effect (12). However, recently it was identified that this saponin derivative presented inhibitory effects on cancer cells.

The aim of the present study was to confirm the anticancer effect of WRC3 and to investigate the possible site of action using murine cancer cell lines.

\section{Materials and methods}

Reagents. Dichloromethane, acetonitrile, acetic anhydride, tin tetrachloride and sodium methoxide were purchased from Aladdin Chemical Co., Ltd. (Shanghai, China). Anhydrous dichloromethane was further purified by distilling with calcium hydride. Anhydrous acetonitrile was purified by distilling over potassium hydroxide. The probe shown in Fig. 1 was purchased from ABIDING 
Technology Co., Ltd. (Chengdu, China). Diosgenin ( $\geq 99.0 \%)$, 3-[4,5-Dimethylthiazol-2-yl]-2,5-diphenyltetrazolium (MTT), and dimethylsulfoxide (DMSO) were purchased from Sigma-Aldrich (St. Louis, MO, USA).

WRC3 synthesis. WRC3 was synthesized as previously described and its purity was determined by high performance liquid chromatograpgy (HPLC, $>98.0 \%$ ) (12). WRC4 was synthesized by our group (purity determined by HPLC, $>98 \%$ ) and was further modified with alkynyl group $(13,14)$ for investigating cell distribution of WRC3.

Cell lines and culture. Mouse B16 melanoma cells (BCRC 60031) were purchased from the Bioresources Collection and Research Center (BCRC, Hsinchu, Taiwan) and cultured in Dulbecco's modified Eagle's medium (DMEM; Gibco Life Technologies, Carlsbad, CA, USA). The cells were supplemented with $10 \%$ fetal bovine serum (FBS; Gibco Life Technologies), $100 \mathrm{U} / \mathrm{ml}$ penicillin and $100 \mu \mathrm{g} / \mathrm{ml}$ streptomycin, at $37^{\circ} \mathrm{C}$ in a $5 \% \mathrm{CO}_{2}$ atmosphere (15).

Animals. All animal experiments were approved by the ethics committee of the West China Hospital, West China Medical School, Sichuan University (Sichuan, China), and conducted according to the Institutional Animal Care and Use Committee Guidelines of the West China Hospital, West China Medical School, Sichuan University. Male Kunming mice (36 \pm 2 g) were provided by the West China Hospital Experiment Animal Center (Chengdu, China). The animals were housed in a comfortable environment under appropriate temperature $\left(22 \pm 1^{\circ} \mathrm{C}\right)$ and humidity $(55 \pm 5 \%)$ control with a $12 \mathrm{~h}$ light $/ 12 \mathrm{~h}$ dark cycle, and allowed free access to food and water.

Cell viability measurement. B16 cells, purchased from the Cell Bank of the Shanghai Institute of Biochemistry and Cell Biology, Chinese Academy of Sciences (Shanghai, China), were cultured in RPMI-1640 (Gibco-BRL, Carlsbad, CA, USA) supplemented with $10 \%$ fetal bovine serum, $100 \mathrm{U} / \mathrm{ml}$ penicillin and $100 \mathrm{U} / \mathrm{ml}$ streptomycin, at $37^{\circ} \mathrm{C}$ and $95 \%$ relative humidity with $5 \% \mathrm{CO}_{2}$. The cell viability assay was performed using MTT. Briefly, cells were plated in 96-well plates at a density of $5 \times 10^{3}$ cells/well, following incubation overnight. A series of diosgenyl derivative (WRC3) were dissolved in DMSO, and diluted with culture media to a series of concentrations $(10,20,40,60$ and $80 \mu \mathrm{M})$. When the cells were exposed to diosgenyl derivatives for $48 \mathrm{~h}, 10 \%$ MTT was added, and cells were incubated for an additional $4 \mathrm{~h}$ at $37^{\circ} \mathrm{C}$. The absorbance was then measured with a microplate reader (Molecular Devices, LLC, Sunnyvale, CA, USA) at $540 \mathrm{~nm}$. All experiments were repeated three times.

Annexin V-fluorescein isothiocyanate (FITC)/propidium iodide (PI) staining of WRC3 treated B16 cells. Annexin V-FITC/PI double-staining assay was used to quantify apoptosis, according to the manufacturer's instructions (KeyGEN, Nanjing, China). B16 cells were treated with WRC3 $(2.5 \mu \mathrm{M})$ for $24 \mathrm{~h}$ and collected. Cells from each well were centrifuged for $5 \mathrm{~min}$ at $2000 \mathrm{xg}$ at $4^{\circ} \mathrm{C}$, washed twice with phosphate-buffered saline and suspended in $300 \mu \mathrm{l}$ binding buffer (Beijing Solarbio Science \& Technology Co., Ltd.,

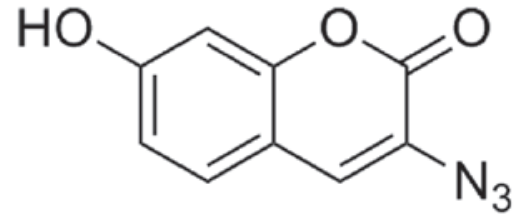

Figure 1. Structure of probe.

Beijing, China). Annexin V-FITC conjugate ( $3 \mu \mathrm{l})$ and $3 \mu \mathrm{l}$ PI solution was added to each cell suspension and incubated for $15 \mathrm{~min}$ at room temperature in the dark. The samples were analyzed on a flow cytometer $\left(\mathrm{MoFlo}^{\mathrm{TM}}\right.$ Cytomation, Modular Flow Cytometer) and Cell-Quest software (version 3.1; BD Biosciences, Franklin Lakes, NJ, USA). Double staining of cells with FITC-Annexin V and PI permits the discrimination between live cells (FITC-PI-), early apoptotic (FITC $\left.{ }^{+} \mathrm{PI}^{-}\right)$, late apoptotic $\left(\mathrm{FITC}^{+} \mathrm{PI}^{+}\right)$and necrotic cells $\left(\mathrm{FITC}^{-} \mathrm{PI}^{+}\right)(16,17)$.

Microscopy analysis distribution of fluorescence in cells. B16 mouse melanoma cells were seeded in 6 -well plates $\left(3 \times 10^{5} / 2 \mathrm{ml}\right.$ per well) containing glass coverslips, and were cultivated in $10 \% \mathrm{FCS} / \mathrm{RPMI}-1640$ medium at $37^{\circ} \mathrm{C}$. Growth medium was supplemented with alkynyl-modified WRC4 $(100 \mu \mathrm{M})$. After growing for 3 days, the cells were washed with 10\% PBS on cover slips, and cells were fixed and permeabilized with paraformaldehyde for $10 \mathrm{~min}$, then subjected to the probe labeling reaction as follows: $0.1 \mathrm{mM}$ probe $/ 1 \mathrm{mM} \mathrm{CuSO} / 2 \mathrm{mM}$ sodium ascorbate were mixed in PBS at room temperature for $30 \mathrm{~min}$. Subsequently, the fixed and labeled cells were rinsed with PBS and stained with PI ( $2 \mu \mathrm{g} / \mathrm{ml}$ in 5\% BSA/PBS) at room temperature for $30 \mathrm{~min}$ (13). Fluorescent images were captured by Nikon ECLIPSE Ti (Chengdu, China) laser scanning confocal microscopy system.

Acute toxicity studies in mice. Twelve Kunming mice were administered WRC3 $(2.5,5.0$ or $7.5 \mathrm{~g} / \mathrm{kg})$ dissolved in $0.9 \%$ normal saline and were observed for a week. After 1 week, the mice were sacrificed by decapitation under pentobarbital anaesthesia (60 mg/kg body weight), and blood and main viscera samples were obtained, prior to biochemical analysis. Serum was collected to measure alanine transaminase (ALT), aspartate transaminase (AST), UREA and creatine (CREA). Liver tissue recovered from the necropsy was divided into two sections, one was used for visual inspection of any morphological changes in the organ tissue samples, and the other was fixed with $10 \%$ formalin, embedded in paraffin, sectioned and stained with hematoxylin and eosin (HE) (Aladdin Chemical Co., Ltd., Shanghai, China) for histological examination using standard techniques. Following HE staining, the slides were observed and the images were captured using a BX51TF BX51 optical microscope (Olympus Corporation, Tokyo, Japan).

Statistical analysis. All data are presented as the mean \pm standard error of the mean. Data were analyzed by one-way analysis of variance followed by post hoc least significant difference test using SPSS software package Version 19.0 for Windows (SPSS, Inc., Armonk, NY, USA). P $<0.05$ was considered to indicate a statistically significant difference. 
Table I. Effects of the WRC3 on AST, ALT, CREA and UREA levels in the serum of rats.

\begin{tabular}{lcccc}
\hline Group & AST $(\mathrm{U} / \mathrm{l})$ & ALT $(\mathrm{U} / \mathrm{l})$ & CREA $(\mu \mathrm{mol} / \mathrm{l})$ & UREA $(\mu$ mol $/ \mathrm{l})$ \\
\hline Control & $104.67 \pm 0.81$ & $35.73 \pm 0.93$ & $49.87 \pm 0.81$ & $4.20 \pm 0.14$ \\
$2.5 \mathrm{~g} / \mathrm{kg}$ of WRC3 & $171.33 \pm 6.58$ & $50.13 \pm 2.89$ & $58.13 \pm 0.35$ & $5.45 \pm 0.35$ \\
$5.0 \mathrm{~g} / \mathrm{kg}$ of WRC3 & $135.60 \pm 7.43$ & $43.33 \pm 0.74$ & $50.67 \pm 0.71$ & $5.77 \pm 0.74$ \\
$7.5 \mathrm{~g} / \mathrm{kg}$ of WRC3 & $128.80 \pm 1.44$ & $37.73 \pm 0.93$ & $62.13 \pm 0.35$ & $6.37 \pm 0.71$ \\
\hline
\end{tabular}

Data are expressed as the mean \pm standard error of the mean; $n=3$. " $P<0.05$, vs. the control group. AST, apsartate transaminase; ALT, alanine transaminase; CREA, creatine.

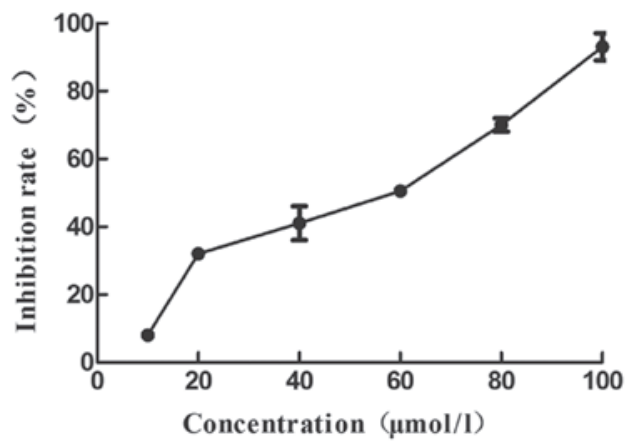

Figure 2. Effect of WRC3 on the proliferation of B16 melanoma cells for $24 \mathrm{~h}$. Following incubation of B16 cells with WRC 3 for $24 \mathrm{~h}$, the rate of inhibition was detected by a 3-(4,5-dimethylthiazol-2-yl)-2,5-diphenyltetrazolium assay. Values are presented as the mean \pm standard error of the mean of three experiments. ${ }^{*} \mathrm{P}<0.05$, vs. control group.

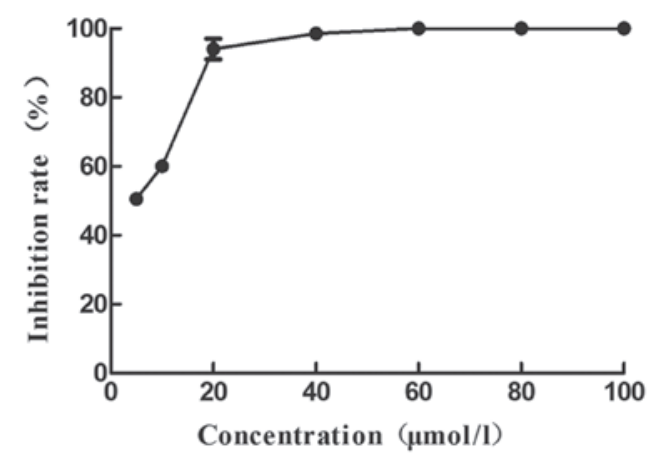

Figure 3. Effect of WRC3 on the proliferation of B16 melanoma cells for $48 \mathrm{~h}$. Following incubation of B16 cells with WRC3 for $24 \mathrm{~h}$, the rate of inhibition was detected by a 3-(4,5-dimethylthiazol-2-yl)-2,5-diphenyltetrazolium assay. Values are presented as the mean \pm standard error of the mean of three experiments. ${ }^{*} \mathrm{P}<0.05$, vs. control group.

\section{Results}

Effect of WRC3 on the proliferation of B16 melanoma cells. The survival rate of B16 melanoma cells treated with WRC3 was determined using an MTT assay. As shown in Figs. 2 and 3, the effect of WRC3 on the survival rate of B16 melanoma cells was examined. Significant WRC3 cytotoxic effects were observed and the viability of the B16 melanoma cells decreased to $37 \%$ at $20 \mathrm{mM}$, and $71 \%$ at $80 \mu \mathrm{M}$ (Fig. 4). Notably, WRC3 significantly inhibited B16 cell survival in a dose-dependent manner, starting a $12.09 \mu \mathrm{M}$ of $\mathrm{IC}_{50}$. In
A

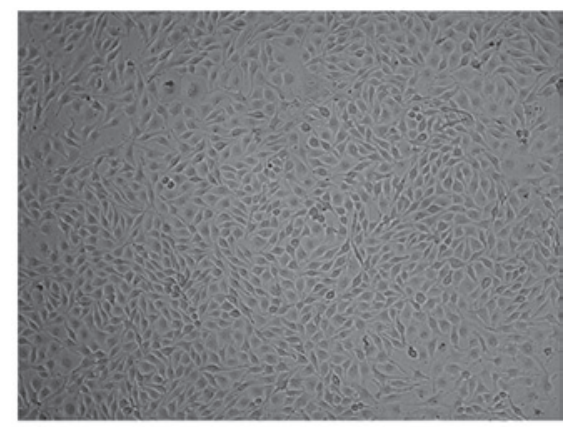

B

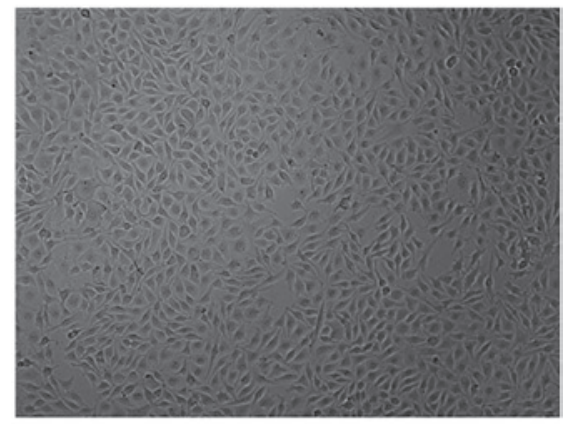

C

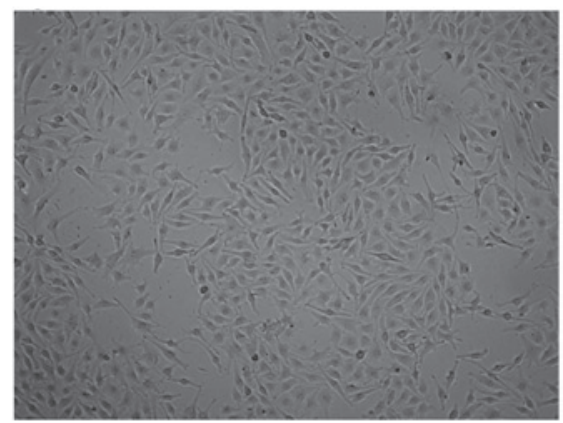

D

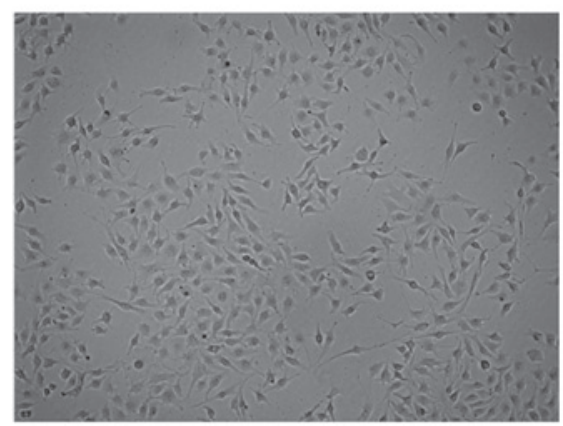

Figure 4. Incubation with WRC3 for $24 \mathrm{~h}$ inhibited the proliferation of and resulted in a morphological change in B16 cells. (A) Control; (B) cells treated with $10 \mu \mathrm{M}$ WRC3; (C) cells treated with $40 \mu \mathrm{M}$ WRC3; (D) cells treated with $80 \mu \mathrm{M}$ WRC3. Phase-contrast microscopic images with no staining; magnification, $\mathrm{x} 40$. 
A

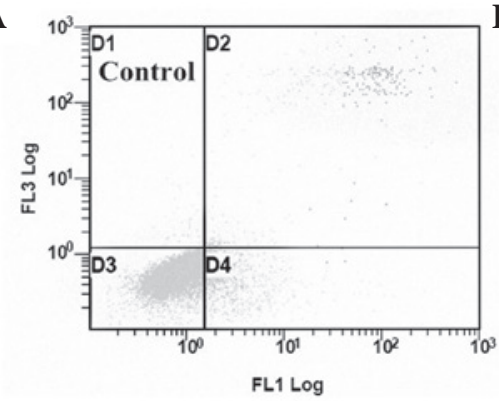

B

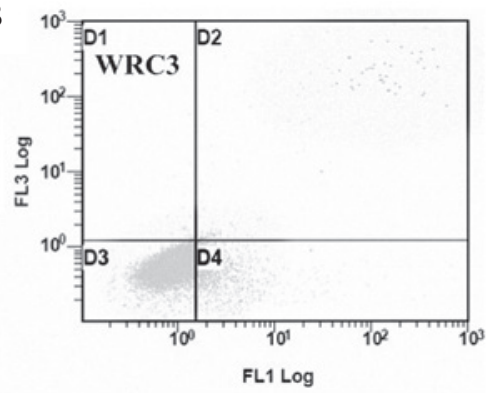

Figure 5. Assessment of apoptosis in WRC3 treated B16 cells. After $24 \mathrm{~h}$ of WRC3 treatment, a flow cytometry assay was used to investigate the apoptosis of B16 cells with Annexin V-fluorescein isothiocyanate/propidium iodide staining. (A) Control group and (B) cells treated with $2.5 \mu \mathrm{M}$ WRC3. Data are the representative from three parallel experiments.

A
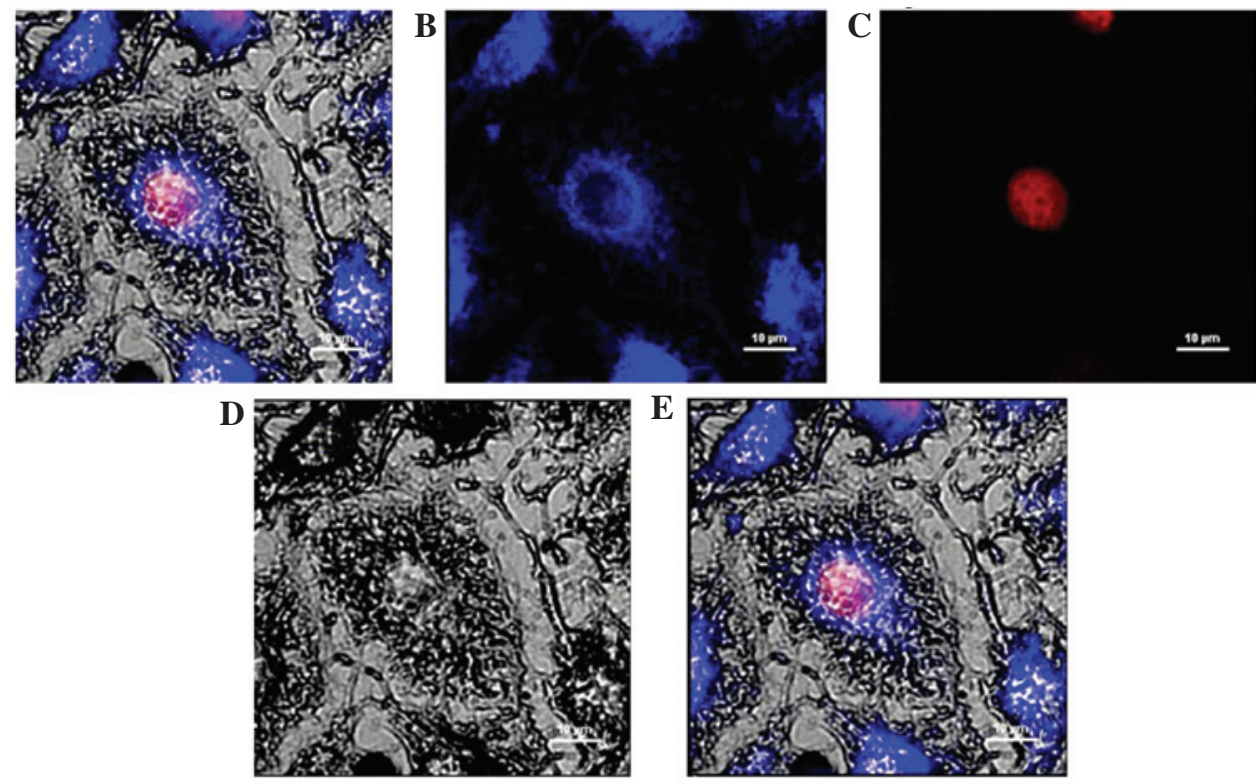

Figure 6. Distribution of WRC4 in B16 melanoma cells. Original magnification x1,000. The cells were incubated with WRC3 for $24 \mathrm{~h}$, washed with PBS and fixed with paraformaldehyde for $10 \mathrm{~min}$, then subjected to a probe-labeling reaction as follows: A total of $0.1 \mathrm{mM}$ probe and $1 \mathrm{mM} \mathrm{CuSO}{ }_{4} / 2 \mathrm{mM}$ sodium ascorbate were added to the PBS at room temperature for $30 \mathrm{~min}$, and then rinsed with PBS and stained with PI ( $2 \mu \mathrm{g} / \mathrm{ml}$ in $5 \%$ BSA/PBS) for $30 \mathrm{~min}$. (A and E) Double staining; (B) WRC4; (C) PI; (D) normal cells. PBS, phosphate-buffered saline; BSA, bovine serum albumin; PI, propidium iodide.
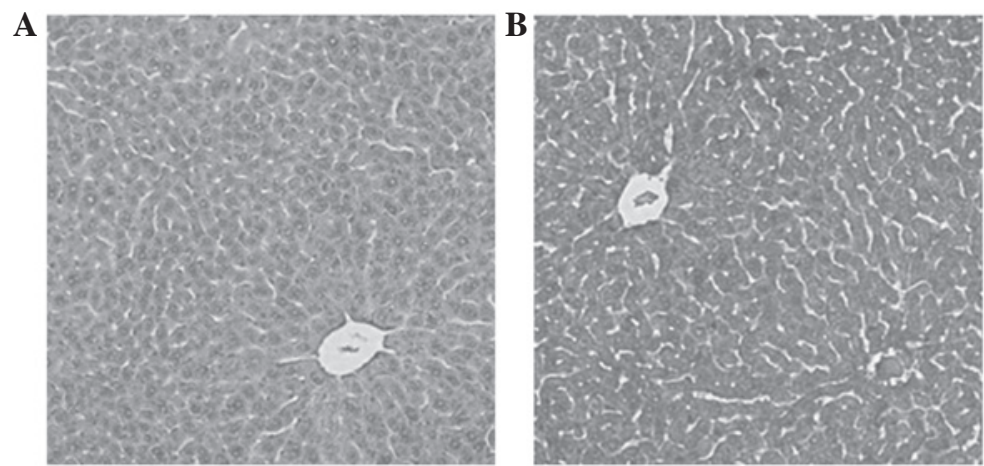

Figure 7. Effects of WRC3 on liver histomorphology in mice. (A) Control, (B) cells treated with $7.5 \mathrm{~g} / \mathrm{kg}$ WRC3. Original magnification, x200.

addition, the survival of the cells treated with $20 \mu \mathrm{M}$ WRC3 for $48 \mathrm{~h}$ was significantly decreased $(<10 \%)$, compared with that at $24 \mathrm{~h}$ (Fig. 3). These results suggest that the inhibitory effect of WRC3 on B16 cells increases in a time-dependent manner. Therefore, a $24 \mathrm{~h}$ treatment time was selected for the subsequent experiments.
Analysis of apoptosis by flow cytometry in B16 cells. Flow cytometric analysis using an Annexin V-FITC apoptosis kit identified apoptosis of B16 cells induced by WRC3. As shown in Fig. 5, the B16 cells were treated with WRC3 $(2.5 \mu \mathrm{M})$ for $24 \mathrm{~h}$, which caused the percentage of early apoptotic cells to increase to $10.64 \%$ and the percentage of late apoptotic 
cells to decrease to $1.15 \%$. In the control group, the early and late apoptotic cells were observed to be 7.17 and $2.42 \%$, respectively. These results suggest that WRC3 predominantly induces early apoptosis in B16 cells.

Visualization of WRC3 in melanoma B16 cells. Fluorescence analysis was used to investigate the distribution of the drug compounds, which may provide information for future drug development. The use of a murine B16 cell line verified that WRC4 was not located in the nucleus, but was distributed in the cytoplasm. In addition, the specific sequestration of WRC4 in the cell was monitored by confocal microscopy, to produce high resolution images. Notably, WRC4 was not located in the nucleus, but was distributed in the cytoplasm (Fig. 6), suggesting that WRC3 may enter the cell and reach the cytoplasm where the primary targets of WRC3 are located, and interfere with cell growth without causing genotoxicity.

Acute toxicity studies in mice. In the acute toxicity study (Table I), no cell death was recorded in any of the animals that received WRC3 $(2.5,5.0$ and $7.5 \mathrm{~g} / \mathrm{kg}$ body weight). In addition, no obvious alterations in organ color were observed in the treated animals, as compared with the control. The levels of ALT, AST, CREA and UREA in the serum of mice treated with various concentrations of WRC3 $(2.5,5.0$ and $7.5 \mathrm{~g} / \mathrm{kg}$ body weight) were not observed to be significantly different (Table I). Histopathological examination of the mice treated with or without WRC3 was evaluated by HE staining to determine the toxicity of WRC3 on organ tissue samples. Fig. 7 revealed that the liver tissue samples of the mice fed with WRC3 did not exhibit significant histological changes, and the structure of the mouse liver lobules and sinusoids were clearly defined, as compared with the control group, suggesting that WRC3 exhibits no hepatotoxicity.

\section{Discussion}

Steroidal saponins have diversity of structure, and are reported to have various biological activities, including anti hyperlipidemic, antibacterial, anti-inflammatory, immunomodulatory, anti-human immunodeficiency virus and anticarcinogenic activities (18). However, the mechanism and site of action underlying the effects of the compounds remains to be elucidated. In the present study, the effects of WRC3, a saponin derivative, was investigated on the proliferation of B16 cells. The $\mathrm{IC}_{50}$ of diosgenin was $>20 \mu \mathrm{M}$ in the B16 cells (data not shown), whereas that of WRC3 was $12.09 \mu \mathrm{M}$, which is lower than that of diosgenin. The results of the present study indicated that WRC3 is able to enter melanoma cells and inhibit the growth of cancer cells in a time and concentration-dependent manner. In addition, the liver of mice treated with WRC3 did not exhibit significant histological changes. Simultaneously, the target of WRC3 in B16 cells was investigated by fluorescence analysis.

A greater understanding of the mechanisms of action associated with anticancer activity will facilitate the use of drug intervention as an important strategy to prevent cancer development (19). A previous study reported that the pathogenesis of numerous diseases, including cancer, are closely associated with aberrantly regulated apoptotic cell death (20).
In the present study, the saponin derivative WRC3 was able to suppress the proliferation of B16 cells in a dose-dependent manner, and the results from the Annexin V-FITC/PI staining assay also demonstrated that WRC3 induced early apoptosis in B16 cells, as compared with the control group. These results indicated that WRC3 may prove beneficial in cancer treatment by mediating apoptotic cell death.

The ability of drugs to enter cells to effect the growth of cancer cells is important. Knowledge regarding the cellular distribution of drugs is important for understanding and predicting drug action and toxicity. Therefore, identifying the targets of a drug is important for drug development (21). The present study investigated the distribution of WRC3 using a fluorescence tracker technique, and demonstrated that WRC4 was not located in the nucleus, but was instead distributed in the cytoplasm. The results of the present study also demonstrated that the fluorescence tracker technique is an important tool for the detection of drug distribution. WRC3 contains a hydroxyl group (chemical handle), which is important for the fluorescence tracker technique. The chemical handle is able to react with terminal alkynyl compounds to obtain alkynyl-WRC3. Alkynyl-WRC3 and 3-azido-7-hydroxy-coumarin reacted in the cells catalyzed by $\mathrm{CuSO}_{4}$ and sodium ascorbate, which may be detected in the cells by fluorescence microscopy. In our previous studies, a WRC3 analogue with alkynes was designed to investigate WRC3 distribution in cells $(22,23)$. WRC3 was observed in the cytoplasm of B16 cells by confocal microscopy (Fig. 6) suggesting that WRC3 can enter into B16 cells to induce the apoptotic cell death of cancer cells without causing genetic toxicity. ALT, AST, CREA and UREA levels in the serum together with tissue H\&E staining, indicate that WRC3 was not toxic to mice organs.

In conclusion, it was demonstrated that a diosgenyl analogue WRC3 inhibits cancer cells in vitro and is not toxic to the liver and kidneys. In addition, the present study also provided a method for locating the action site of WRC3 using click-chemistry, which is important for the determination of the drug target in the cells by fluorescence labeling. The results further provided evidence that the sugar moiety of steroidal saponins may be crucial for their antitumor activity. These findings were concordant with those of a previous study demonstrating that the anti-cancer effects of steroidal saponins with sugar moieties are markedly higher compared with those of parent nucleus diosgenin (7). Saponins have the potential to be developed as anticancer agents, and thus require further investigation.

\section{Acknowledgements}

This study was supported by the China National ' 12.5 ' Foundation (grant no. 2011BAJ07B04) and National Natural Science Foundation of China (grant no. 20972105).

\section{References}

1. LiH,Huang W, Wen Y,Gong G,Zhao Q and Yu G: Anti-thrombotic activity and chemical characterization of steroidal saponins from Dioscorea zingiberensis C.H Wright. Fitoterapia 81: 1147-1156, 2010.

2. Liu W, Huang W, Sun W, Zhu Y and Ni J: Production of diosgenin from yellow ginger (Dioscorea zingiberensis C.H. Wright) saponins by commercial cellulase. World J Microbiol Biotechnol 26: 1171-1180, 2010. 
3. Sparg SG, Light ME and van Staden J: Biological activities and distribution of plant saponins. J Ethnopharmacol 94: 219-243, 2004.

4. Jung DH, Park HJ, Byun HE, Park YM, Kim TW, Kim BO, Um SH and Pyo S: Diosgenin inhibits macrophage-derived inflammatory mediators through downregulation of CK2, JNK, NF-kappaB and AP-1 activation. Int Immunopharmacol 10: 1047-1054, 2010.

5. Gong G, Qin Y and Huang W: Anti-thrombosis effect of diosgenin extract from Dioscorea zingiberensis C.H. Wright in vitro and in vivo. Phytomedicine 18: 458-463, 2010.

6. Huang CH, Liu DZ and Jan TR: Diosgenin, a plant-derived sapogenin, enhances regulatory T-cell immunity in the intestine of mice with food allergy. J Nat Prod 73: 1033-1037, 2010.

7. Tong QY, He Y, Zhao QB, Qing Y, Huang W and Wu XH: Cytotoxicity and apoptosis-inducing effect of steroidal saponins from Dioscorea zingiberensis Wright against cancer cells. Steroids 77: 1219-1227, 2012

8. Rivera DG, Concepción O,Perez-Labrada K and Coll F: Synthesis of diamino-furostan sapogenins and their use as scaffolds for positioning peptides in a preorganized form. Tetrahedron 64 : 5298-5305, 2008.

9. Kvasnica M, Budesinsky M, Swaczynova J, Pouzar V and Kohout L: Platinum (II) complexes with steroidal esters of L-methionine and L-histidine: Synthesis, characterization and cytotoxic activity. Bioorg Med Chem 16: 3704-3713, 2008.

10. Huang B, Du D, Zhang R, Wu X, Xing Z, He Y and Huang W: Synthesis, characterization and biological studies of diosgenyl analogues. Bioorg Med Chem Lett 22: 7330-7334, 2012.

11. Qin Y, Wu X, Huang W, Gong G, Li D, He Y and Zhao Y: Acute toxicity and sub-chronic toxicity of steroidal saponins from Dioscorea zingiberensis C.H. Wright in rodents. J Ethnopharmacol 126: 543-550, 2009.

12. Zhang R, Huang B, Du D, Guo X, Xin G, Xing Z, Liang Y Chen Y, Chen Q, He Y, et al: Anti-thrombosis effect of diosgenyl saponins in vitro and in vivo. Steroids 78: 1064-1070, 2013.

13. Hsu TL, Hanson SR, Kishikawa K, Wang SK, Sawa M and Wong CH: Alkynyl sugar analogs for the labeling and visualization of glycoconjugates in cells. Proc Natl Acad Sci USA 104: 2614-2619, 2007.
14. Sawa M, Hsu TL, Itoh T, Sugiyama M, Hanson SR, Vogt PK and Wong CH: Glycoproteomic probes for fluorescent imaging of fucosylated glycans in vivo. Proc Natl Acad Sci USA 103: 12371-12376, 2006.

15. Kim KS, Kim JA, Eom SY, Lee SH, Min KR and Kim Y: Inhibitory effect of piperlonguminine on melanin production in melanoma B16 cell line by downregulation of tyrosinase expression. Pigment Cell Res 19: 90-98, 2006.

16. Jadeja RN, Thounaojam MC, Devkar RV and Ramachandran AV: Clerodendron glandulosum.Coleb extract prevents in vitro human LDL oxidation and oxidized LDL induced apoptosis in human monocyte derived macrophages. Food Chem Toxicol 49: 1195-1202, 2011

17. Gong G, Qin Y, Huang W, Zhou S, Yang X and Li D: Rutin inhibits hydrogen peroxide-induced apoptosis through regulating reactive oxygen species mediated mitochondrial dysfunction pathway in human umbilical vein endothelial cells. Eur J Pharmacol 628: 27-35, 2010.

18. Tuntiwechapikul W, Taka T, Songsomboon C, Kaewtunjai N, Imsumran A, Makonkawkeyoon L, Pompimon W and Lee TR: Ginger extract inhibits human telomerase reverse transcriptase and c-Myc expression in A549 lung cancer cells. J Med Food 13: $1347-1354,2010$

19. Gong G, Qin Y, Huang W, Zhou S, Wu X, Yang X and Zhao Y, Li D: Protective effects of diosgenin in the hyperlipidemic rat model and in human vascular endothelial cells against hydrogen peroxide-induced apoptosis. Chem Biol Interact 184: 366-375, 2010.

20. Hu M, Xu L, Yin L, Qi Y, Li H, Xu Y, Han X, Peng J and Wan X: Cytotoxicity of dioscin in human gastric carcinoma cells through death receptor and mitochondrial pathways. J Appl Toxicol 33: 712-722, 2013.

21. Hanson S, Best M, Bryan MC and Wong $\mathrm{CH}$ : Chemoenzymatic synthesis of oligosaccharides and glycoproteins. Trends Biochem Sci 29: 656-663, 2004

22. Rostovtsev VV, Green LG, Fokin VV and Sharpless KB: A stepwise huisgen cycloaddition process: copper (I)-catalyzed regioselective 'ligation' of azides and terminal alkynes. Angew Chem Int Ed Engl 41: 2596-2599, 2002.

23. Wang Q, Chan TR, Hilgraf R, Fokin VV, Sharpless KB and Finn MG: Bioconjugation by copper(I)-catalyzed azide-alkyne [3+2] cycloaddition. J Am Chem Soc 125: 3192-3193, 2003. 